\title{
Food Insecurity among College Students: An Exploratory Study
}

\author{
Mukigi $\mathrm{D}^{1}$, Thornton $\mathrm{K}^{2}$, Binion $\mathrm{A}^{2}$, Brown $\mathrm{K}^{2}$, Church $\mathrm{M}^{2}$, Cook $\mathrm{M}^{2}$, Henry $\mathrm{D}^{3}$, Hopkinson $\mathrm{J}^{2}$, Masucci $\mathrm{C}^{2}$, \\ Pruett $\mathrm{J}^{2}$, Rogers $\mathrm{M}^{2}$, Singleton $\mathrm{O}^{2}$, Vichi-Miller $\mathrm{V}^{2}$, Wofford $\mathrm{R}^{2}$, and Brown $\mathrm{O}^{* 1}$ \\ ${ }^{1}$ Department of Nutrition, Dietetics and Hospitality Management, Auburn University, Auburn, AL, USA \\ ${ }^{2}$ Hunger Solutions Institute, College of Human Sciences, Auburn University, Auburn, AL, USA \\ ${ }^{3}$ Department of Educational Foundations, Leadership, and Technology, Auburn University, Auburn, AL, USA
}

${ }^{*}$ Corresponding author: Brown O, Department of Nutrition, Dietetics, \& Hospitality Management, 102 A Poultry Science Building, Auburn University, AL 36849, USA, Tel: 334-844-3161, E-mail: onb0001@auburn.edu

Citation: Mukigi D, Thornton K, Binion A, Brown K, Church M, et al. (2018) Food Insecurity among College Students: An Exploratory Study. J Nutr Health Sci 5(1): 106. doi: 10.15744/2393-9060.5.106

Received Date: February 13, 2018 Accepted Date: March 20, 2018 Published Date: March 21, 2018

\begin{abstract}
College students are characteristically vulnerable to food insecurity because of the increase in the cost of higher education. Students face competing budget demands that may compromise food dollar allocation. This study explored the experiences of 17 food insecure college students using in-depth semi-structured interviews. Analysis of audiotaped interview data was performed using emergent theme analysis. The participants narrated their experiences with food insecurity, how it affects them and how they cope with food insecurity. Specific themes included: (1) history of food insecurity; (2) competing financial demands; (3) coping with food insecurity; (4) effects of food insecurity on academics; (5) effects of food insecurity on health; and (6) role of support systems. Food insecurity is a salient issue among college students and it can have a negative impact on student academic success and health. University communities should respond by identifying affected students, establishing support systems such as food pantries and creating campus awareness of the issue.
\end{abstract}

Keywords: College students; Food insecurity; Coping strategies; Interview

\section{Introduction}

The United States Department of Agriculture (USDA) defines food insecurity as "a household-level economic and social condition of limited or uncertain access to adequate food" [1]. Reports from the 2016 Current Population Survey indicate that $12.3 \%$ of United States (US) households are food insecure [2]. Recent studies have been conducted regarding food insecurity on college campuses and available literature estimate that 12 to 59\% of college students experience some level of food insecurity [3-9]. The Hunger in America 2014 National Report prepared for Feeding America indicates that 10\% of their 46.5 million clients were currently students in higher education [10]. These data support the idea that hunger and food insecurity are prevalent on college campuses. However, there is lack of quantitative study that explores the effects of food insecurity on daily lives of college students.

It is projected that by the year 2020,65\% of all jobs in the US economy will require postsecondary education [11]. It is estimated that there are approximately 19 million students attending institutions of higher learning [12]. Attending college and earning a degree is perceived as an essential step to ensure success in life and therefore, this perception may have significantly contributed to the increase of enrollment of typically underrepresented populations such as first-generation college attendees and students from low socioeconomic backgrounds [5,11-3].

Results from multiple studies indicate that food insecurity have negative impacts on the grade point average (GPA) of college students [4-9]. One study has indicated that food insecurity is associated with adult cognitive impairment and academic hiatus [13]. This provides an insight into the potential negative impacts of food insecurity on students' educational success.

College students are often referred to as emerging adults that encounter life-changing experiences as they transition to life away from home [14]. These experiences may bring about stress among students as they try to adapt to life away from home. Food insecurity has been identified by a recent study as an important cause of stress among college students and it may contribute to undesirable eating habits in this population. Stress has also been associated with eating disorders such as binge eating and meal restriction $[3,15]$. Whether eating disorders are associated with food insecurity among college students is unknown.

Food insecurity negatively affects dietary intake, for example, it is associated with intake of energy dense foods and the lack of diet variation [16]. In a study that was conducted to establish the relationship of college student food security and fruit and vegetable 
intake, a significant decrease in the intake of fruits and vegetables were associated with increased severity of food insecurity in college students who resided in housing where meals were not provided [15]. Dietary patterns established during college years are likely to be continued throughout life [18]. Therefore, it is important for researchers to develop interventions to teach and encourage healthy eating on a value menu.

Past studies investigating food insecurity among college students have mostly used quantitative methods to present demographic characteristics and prevalence of food insecurity among sampled students [3-9]. Consequently, little is known about the daily experiences, coping mechanisms and consequences of food insecurity among college students.

The objectives of our study were to investigate the lived experiences of food insecure college students in a southern public institution and bring awareness on what happens when college students cope with food insecurity.

\section{Methods}

This qualitative study used individual interviews to explore the experience of food insecurity among college students enrolled at a public university in southeast United States. Participants were recruited using flyers posted on notice boards throughout campus. Students who were struggling to make ends meet and having disrupted eating patterns, reduced food intake, and reduced food quality due to lack of financial resources were eligible to participate. Interested students responded to the flyer via email and the researchers scheduled the interview appointments at the convenient time for both parties. All participants provided written informed consent before being interviewed and were offered a $\$ 20.00$ grocery store gift certificate after study participation. Study approval was provided by the Southeastern University Institutional Review Board (IRB).

Participants completed one semi-structured in person interview that lasted between 30-45 minutes. A set of two trained student researchers conducted the interviews using an interview guide shown in Appendix 1. The interviews were conducted privately in a closed office. Interviewers reassured the participants of the confidentiality of the information that they will share and encouraged them to speak freely about their experiences with food insecurity. All interviews were audio recorded using an audio recorder and were transcribed verbatim by the student researchers.

The interview data were reviewed using qualitative software, Atlas.ti (Berlin, Germany). The researchers coded the data into themes and sub-themes. The codebook was developed by a graduate student researcher after extensive familiarization with the data. The researchers read and re-read the transcripts extensively using the constant comparative technique of the grounded theory [19]. To methodically understand the participants experiences, coding and analysis were conducted concurrently [20,21]. We reached theoretical data saturation with 14 individual interviews, but we continued with the interviews to ensure no new themes emerged in the next few interviews [19]. We reached data repetitiveness and informational redundancy at 17 interviews.

To check for inter-analyst agreement, two researchers who were unfamiliar with the coding scheme were trained using quotations from the sample. After the training, the two researchers separately coded one randomly selected transcript. The inter-analyst agreement was $87 \%$ and met the established standard for agreement [22].

\section{Results}

During the study period (January to February 2017), 19 students responded to the recruitment flyers. Of the 19 students, 2 were screened out because they did not meet eligibility criteria as determined by the screening questions that were asked before the start of the semi-structured interview. The participants were asked if they were struggling financially, having disrupted eating patterns, reduced food intake and/or reduced quality of food and if they answered yes to these questions, they were found to be eligible to participate in the study. Most of the participants were female (71\%), and slightly more than half of the participants were Caucasian. Sixty five percent of the participants were undergraduates and $35 \%$ were graduate students. Two participants were non-traditional students, one was married, and each had a child. Table 1 provides a further breakdown of the study's participants.

\begin{tabular}{|c|c|}
\hline Characteristic & n (\%) \\
\hline \multicolumn{2}{|c|}{ Age } \\
\hline $20-30$ & $14(82)$ \\
\hline $31-40$ & $1(6)$ \\
\hline $41-50$ & $1(6)$ \\
\hline$\geq 51$ & $1(6)$ \\
\hline Sex & $12(71)$ \\
\hline Female & $5(29)$ \\
\hline Male \\
\hline \multicolumn{2}{|c|}{ Marital Status } \\
\hline \multicolumn{2}{|c|}{ Single } \\
\hline
\end{tabular}




\begin{tabular}{|c|c|}
\hline Characteristic & n (\%) \\
\hline Married & $1(6)$ \\
\hline \multicolumn{2}{|c|}{ Children } \\
\hline No & $15(88)$ \\
\hline Yes & $2(12)$ \\
\hline \multicolumn{2}{|c|}{ Race/ethnicity } \\
\hline African American & $2(12)$ \\
\hline Asian & $5(29)$ \\
\hline Caucasian & $9(53)$ \\
\hline Latina/Hispanic & $1(6)$ \\
\hline \multicolumn{2}{|c|}{ Place of Birth } \\
\hline USA & $14(82)$ \\
\hline Another country & $3(18)$ \\
\hline \multicolumn{2}{|c|}{ Classification } \\
\hline Undergraduate & $11(65)$ \\
\hline Graduate & $6(35)$ \\
\hline
\end{tabular}

Table 1: Participant Characteristics $(\mathrm{n}=17)$

After data analysis, we identified the following specific themes: (1) history of food insecurity; (2) competing financial demands; (3) coping with food insecurity; (4) effects of food insecurity on academics; (5) effects of food insecurity on health; and (6) role of support systems. The themes, sub-themes and illustrative quotations are listed in Table 2.

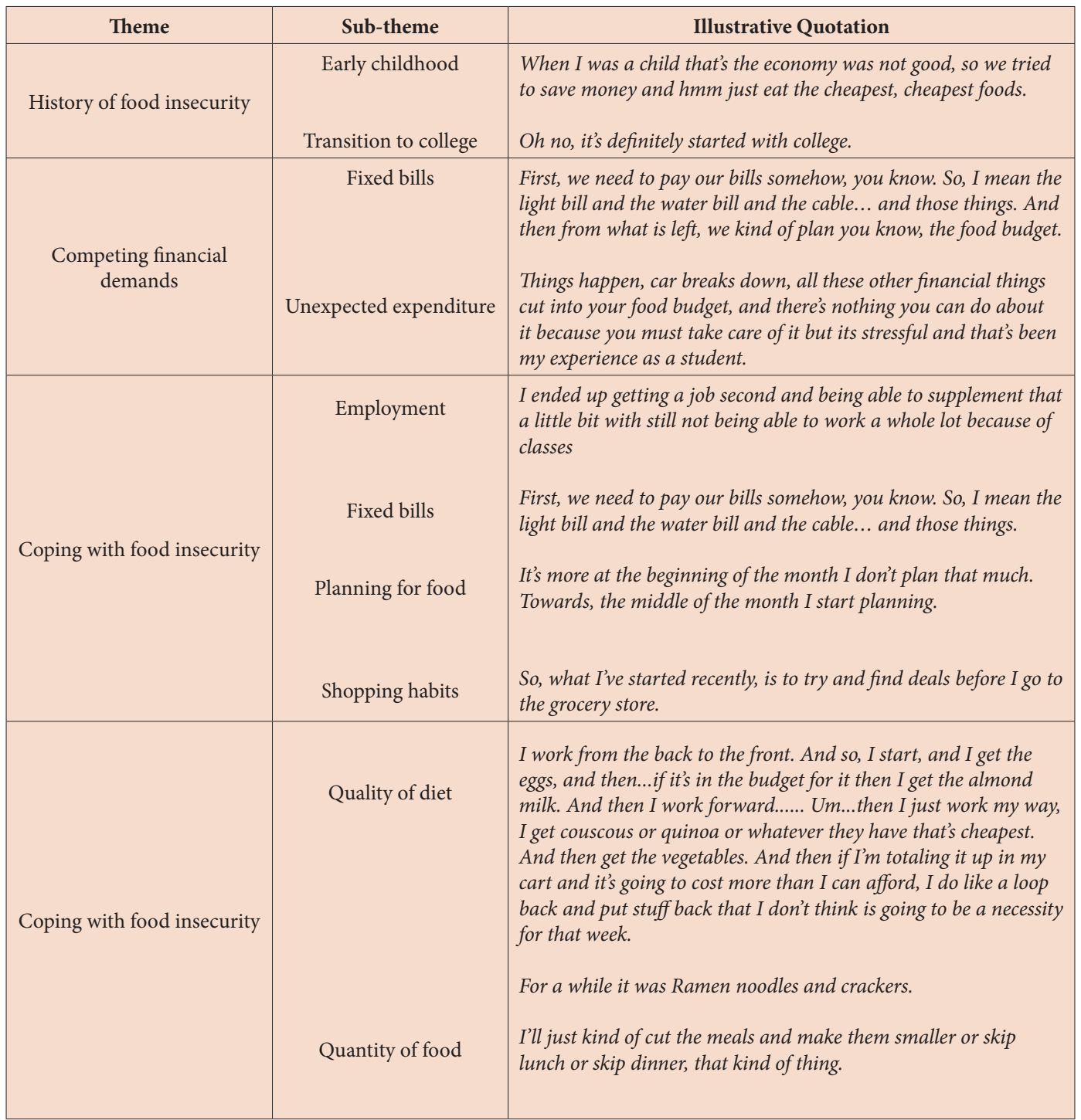




\begin{tabular}{|c|c|c|}
\hline Theme & Sub-theme & Illustrative Quotation \\
\hline $\begin{array}{l}\text { Effects of food insecurity on } \\
\text { academics }\end{array}$ & $\begin{array}{l}\text { Classroom behavior } \\
\text { Focus on academics }\end{array}$ & $\begin{array}{l}\text { Um there were definitely a lot of times where like I was falling } \\
\text { asleep in class. } \\
\text { There are times when I'm really hungry and not able to focus on } \\
\text { school work or whatever I'm working on. } \\
\text { I feel like my grades suffer, because like I feel like I can't stay up } \\
\text { all night and study like some people can because I'm just like } \\
\text { physically exhausted. }\end{array}$ \\
\hline $\begin{array}{l}\text { Effects of food insecurity } \\
\text { on health }\end{array}$ & $\begin{array}{l}\text { Mental health } \\
\text { Physical health } \\
\text { Social health }\end{array}$ & $\begin{array}{l}\text { It's depressing, very depressing. Ahhh, I find myself struggling. Am } \\
\text { I going to eat today? Am I going to study today? } \\
\text { If I don't eat enough, I don't feel good, and I will stay in bed all } \\
\text { day long, and I hate to stay in bed all day long. } \\
\text { When I'm hungry, I'm hungry and that can be over whelming, and } \\
\text { your body is telling you, you need to do something about it. The main } \\
\text { thing is I just get really irritable. I feel bad because I know logically } \\
\text { you're taking things out on other people and at that point I'm like you } \\
\text { need to take a break from people until you get food in your system. }\end{array}$ \\
\hline Role of support systems & $\begin{array}{l}\text { Asking for help from } \\
\text { family or friends }\end{array}$ & $\begin{array}{l}\text { I'm very independent so I don't like to ask for help or to ask for } \\
\text { especially like for money or stuff like that. } \\
\text { I borrowed some of my roommates' food, took them up on their } \\
\text { offer to buy me food a couple of times. } \\
\text { I volunteered at, um, the community market and seeing the people that } \\
\text { were there, even though it was actually at that time that I was strug- } \\
\text { gling, like, the most, I still didn't feel like I deserved it like they did. }\end{array}$ \\
\hline
\end{tabular}

Table 2: Themes, Sub-themes and Quotations of the Experiences of Food Insecure Students

\section{History of Food Insecurity}

Some participants discussed how food insecurity or lack of food was not a new experience to them. Most of the participants discussed how they remember not having enough food when they were children, how their families struggled to put food on the table and some talked about how they became food insecure when they joined college:

Early Years: I can't say it a new experience. I have dealt with it growing up. I have dealt with it in my adulthood, I have dealt with on many occasions and it becomes almost second nature to me.

Growing up there was some food items I wanted, and we couldn't afford. I wanted healthy food growing up, I wanted fresh fruits and vegetables. I wanted healthy fats.

Transition to College: Um but not having enough food or really like that falling onto me was a new experience.

Oh no, it's definitely started with college.

\section{Competing Financial Demands}

The participants talked about how expenditures such as water and medical bills, and other unexpected expenses reduced their food dollar allocation. The participant's prioritized other expenses over food and money that was left was used for food:

Fixed Bills: First, we need to pay our bills somehow, you know. So, I mean the light bill and the water bill and the cable... and those things. And then from what is left, we kind of plan you know, the food budget

Unexpected Expenditure: Some participants reported unexpected expenses coming up and further straining their limited resources:

Yes! Um, things come up, you know, when the sole comes off your tennis shoes and you planned to wear them for another 6 months, you know, there's nothing else to do than go buy a new pair of tennis shoes.

And, so like I have to budget medical expenses stuff after that. And then whatever is left over is food.

\section{Coping with Food Insecurity}

Employment: Three participants reported working off campus with the aim of raising money for their upkeep:

I work two jobs, and I'm a full-time student, but one of my jobs pays bi-weekly and it's only about $\$ 100$, and then the other job, I get paid once every 10 weeks and it's also about $\$ 100$. 
I am currently working a third shift job that I get off at 6.30 in the morning.

I work odd jobs like tutor people.

Planning for Food: When the participants were asked how they planned and budgeted for their meals, it was clear from the responses that there are those who do not plan until they are almost running out of money... "It's more at the beginning of the month I don't plan that much. Towards, the middle of the month I start planning," others who weigh their options before making a decision on how they would spend their money on food.... "Like trying to go to the grocery store and buy food versus eating out. That definitely is a big difference," and there are those who are careful and skillful planners... "Yeah just like really careful budgeting to make sure it would make to the end of the semester," and "Um, usually like I'll write a little like check-list on my phone, and like check the prices, and I'll be like ok well do I really need this right now?" and like if I don't I won't get it and then like I usually check in my cart like 'ok this might be a little too much', and I'll go put stuff back".

Shopping Habits: When the participants were asked to discuss how they go about their grocery shopping, it was evident that majority of them made grocery lists based on the meals they have in a day:

I definitely have to make a list. On my phone, I must make a list and now I'm getting to where I'm really specific like I'll have breakfast, lunch, snack, dinner, what drinks I need and like miscellaneous stuff I need like paper plates and those stuff.

One participant reported making a grocery list based on how the food items are organized in the store:

I'm weird, I organize my list specifically where each section is, so I don't have to go back and forth, so I don't see things, I don't need and get tempted to buy them. I literally organize my list so I can go in, grab what I need and get out, I can grab what I need and be out in half an hour.

Another participant reported that he knew exactly which isle to go to get a specific food item and how much he would spend during a grocery shopping trip:

I go to the store; I know exactly what aisle to go to and what to get and how much I'm going to spend.

When the participants were asked to discuss the steps they took during their food crisis, they discussed how they settled on consuming foods that were cheap, lacked variety and less nutritious because they could not afford healthier options.

Quality of Diet: I sometimes eat vitamins and rice and flour. That will give me energy.

I'll buy, um, just some more unhealthy things that will last longer um, and just get by, by buying the cheap things.

I ate a lot of ramen. My ramen game was strong. I would do like ramen and siracha or ramen and eggs-I ate a lot of ramen and eggs because eggs are really cheap. Um, I ate a lot of oatmeal and grits, like to the point where I never want to look at oatmeal or grits ever again.

Although the participants wished to eat more nutritious food, the cost of the more healthier food options were prohibitive, and they did not consider the quality of food they were purchasing but the cost of it:

I can't afford the healthy option.

I don't consider nutrition, I look at the cost. Hey it's cheap....can I afford this?

Most of the respondents expressed the desire to consume more fresh produce like fruits and vegetables but the cost was beyond their reach,

The hardest thing is the fresh...the fresh fruits and vegetables. You know, that's the hardest thing to get whenever you're on an extremely fixed income.

One participant had no desire to purchase fruits because they were not filling yet they were expensive:

You have grapes, bananas and things like that, they're pretty much a snack. It's not something I am going to eat and get full off them so, I can't go another 8 hours before eating. Am I going to consume that (fruits) and in 30 minutes I want something else...in an hour or so. Why waste my \$3 to 5 on something and I can hold on my \$3 to 5 and spend on something I can get full off.

Quantity of Food: Most of the participants employed coping strategies such as cutting the size of their meals and skipping meals to ensure they have food:

I'll just kind of cut the meals and make them smaller or skip lunch or skip dinner, that kind of thing.

Making sure to only eat half of my meal anytime I ever went to eat on campus.

The participants described how hungry they were when they didn't have money to buy food and how they did not have energy to stay awake in class because they were not getting enough food: 
When I actually was hungry and like couldn't just go to the store and buy something or couldn't go on campus and get something because I didn't have that money anymore it was kinda like "what do I do now?

I'm falling asleep in class because like I'm not getting enough to eat, and I'm just... not fueled I guess is what it is.

\section{Effects Food Insecurity on Academics}

When the participants were asked how being hungry affects them as students, they talked about how their school work is negatively affected by hunger, they talked about how they would sleep in class and not focus and therefore their grades suffered in the long run.

Um there were definitely a lot of times where like I was falling asleep in class.

There are times when I'm really hungry and not able to focus on school work or whatever I'm working on.

\section{Effects Food Insecurity on Health}

From the interviews, it was apparent that food insecurity negatively affected the health of most of the participants. The participants mental, physical and social health were negatively affected by food insecurity:

Mental Health: Another thing, it affects my mood. I get angry. I have to separate myself from other people, I am not a pleasant person. It's depressing, very depressing. I find myself struggling, Am I gonna eat today? Am I gonna study today? It does cause me stress.

It just makes me cranky, like you know, hangry, I guess but it makes me really crabby. I get, I get really irritated if I get hungry and I get really snappy.

Physical Health: I don't eat as much like I feel like throughout the day I'm just tired, like I'm not getting energy from my food, and so like, I'm sure that doesn't help with the focus.

I was noticing like throughout the semester that I wasn't staying awake and I knew that was because calories.

I'm pretty athletic.... that was something that was affected by like not having enough calories....so I know I can't go workout from a calorie standpoint, I can't afford that. I wish I could do this (exercise) but I don't have enough food to sustain me to do this um so I'm gonna chose not to exercise.

Social Health: Socially it's hard. Uh, because, a lot of people they're like social things, like hey let's go out to the movies or let's go out to dinner or something and I'm like oh no.

So, I wasn't really able to go to events with a lot of my peers because again they all cost money.

From social standpoint, I couldn't go out to eat um definitely like whenever I was making money was saving it for food so wasn't doing anything-any of the other activities.

I didn't join any of the clubs, didn't buy any of the t-shirts, didn't do any of that stuff and just like out of necessity.

So, I wasn't really able to go to events with a lot of my peers because again they all cost money.

\section{Role of Support Systems}

There were mixed responses when the participants were asked if they feel comfortable asking for help/support from their parents, relatives or friends, and whether they utilize community support resources like the food pantry. Some were comfortable asking for help: "I borrowed some of my roommate's food, took them up on their offer to buy me food a couple of times," while others were not comfortable: "So, I'm not the one to like go out and ask. I mean I even feel bad asking for [food from] my parents."

Some participants reported that they were comfortable utilizing the food pantry on campus, "It doesn't bother me at all," while others felt they did not need the food pantry or deserve food assistance:

Oh. I don't need those, I have never used that or anything.

I was struggling, like, the most, I still didn't feel like I deserved it like they did and I didn't like want, you know, I didn't want to seek out that help.

\section{Discussion}

Previous studies have provided statistics on the prevalence of food insecurity among college students, but the voices of the food insecure students are absent in these studies [4-9,11,3]. Consequently, very little information is known about the factors that influence food insecurity among college students, how they cope with food insecurity and how food insecurity affects their wellbeing and success as students. This study aimed at filling that gap of information using semi-structured interviews to explore the lived experiences of the food insecure college students. 
The participants in this study expressed that their food insecurity was either something they have lived with since childhood or something new experienced when they joined college. These findings may be partly explained by the fact that there has been tremendous increase in college enrollment by students from low socioeconomic backgrounds and the fact that college students often termed as emerging adults often lack food preparation knowledge, skills and resources which when combined may increase their risk for food insecurity [5,22].

Some participants in this study reported working multiple jobs to supplement their income to ensure they have financial resources to purchase food. They expressed understanding that working affected their classwork because they had less time for studying and completing projects. One past study found that in households in which the household head has multiple jobs and works different shifts have increased risk of food insecurity as compared to similarly placed households in which the head holds one full-time job. It is not clear if risk of food insecurity is due to complicated schedule or unstable income [23]. To the best of our knowledge, there has been no research that has explored the relationship between food insecurity and work hours among college students. Therefore, we recommend that future studies investigate this topic.

Students often have financial demands that compete with their food dollar. The participants talked about prioritizing fixed bills and then using the little money that is "left over" to purchase food. They also talked about unexpected expenses like medical costs and fixing a broken car. Fixed and unexpected expenses have been found to increase the risk of food insecurity [24,25]. Additionally, the cost of books, living expenses and tuition has increased by $46 \%$ since 2001 nationwide [26]. All these factors increase the odds of an average college student becoming food insecure.

Budgeting and financial skills are important in managing limited resources. The participants in this study had various levels of these skills, for instance one participant reported that he/she only budget/plan for meals when resources dwindle, and another participant reported that he/she makes a grocery list, knows exactly how much to spend and knows exactly which isles to go to in the grocery store. Previous research focused on low income populations show that food security can be improved by optimization of food resources through skills [13]. Future studies should focus on imparting food resource management skills and knowledge among college students.

The participants often reported decreasing the quality or quantity of their meals to ensure they stretch their food resources. They reported eating cheap meals, cutting the size or skipping some meals in order to have food to eat later. These findings affirm other studies that found that food insecure individuals purchase inexpensive processed food items and decrease amounts of food eaten when resources decrease $[27,28]$. One participant talked about eating very little meals even when she has adequate food because she has extreme fear of running out of food and in contrast, another one talked about binge eating when food is available. Meal restriction and binge eating behaviors have been reported in previous studies, where food insecure individuals were found to decrease amount of food eaten when resources reduce and compensate by overeating when more food is available. These behaviors may lead to the development of eating disorders. Additionally, research has shown positive associations between food insecurity and eating disorders [15].

In the present research, food insecurity negatively affected the participant's academic, mental and social wellbeing. Poor academic performance has been linked to food insecurity in children, adolescents and college students [9]. A recent study reported that the risk of anxiety and depression of food insecure freshmen is 3 times higher than their peers [3]. Similarly, another study found that poor nutrition is the second leading cause of mental health concerns among college students [29]. Although the participants talked about avoiding hanging out with friends during meal times because they did not have money to spend, it can be implied that the stigma associated with being food insecure played a role in their social isolation.

Majority of the participants in this study expressed reluctance in seeking or receiving food assistance from friends, parents, partners or food pantries. The major barrier noted by the researchers is the rationalization by the food insecure students that lacking adequate food was a normal experience and that they did not need or deserve help. Additionally, participants expressed their desire to be independent and feeling embarrassed about asking for help. Similar barriers have been reported among the general population and college students [30-32]. These barriers may contribute to low utilization of available resources among college students and this is supported by findings of a study that established that only $4 \%$ of students who are aware of the resources on campus actually utilized them [33]. There is need for campuses to initiate conversations and create awareness on food insecurity with the aim of destigmatizing food insecurity.

University administrators should consider strategies to assist affected students, for example, establish on campus community gardens and food pantries. The universities can also negotiate with the private companies running cafeterias on campus to offer subsidized nutritious meals and to establish food recovery programs with the aim of assisting needy students.

This exploratory study brings awareness to the lived experiences of food insecure college students and adds the voice of the food insecure college students to the growing knowledge on this issue. The findings of this study show that there are negative academic, health and nutrition related effects associated with food insecurity among college students. The findings of this study also show that food insecure students have added stress that affect their academic success, and that food insecure college students engage in dietary habits and sleep behaviors that might lead to eating and sleep disorders. There is need for multi-university 
ethnological and/or longitudinal studies to explore how food insecurity affects college students' academics, nutrition and health during undergraduate and graduate studies, and use the information to tailor make interventions targeting dietary/nutrition, sleep and stress management behaviors of college students.

University academic counselors, nutrition and health practitioners can use this information to enhance their problem diagnosis to include screening for food insecurity to better serve the students. Universities can establish food pantries and/or provide subsidized meals for the students in need and can also engage in conversations with the aim of creating awareness and destigmatizing food insecurity and therefore providing support to students who would otherwise struggle in silence.

\section{Limitations}

One limitation of this study is that the participants were a mixture of, traditional and non-traditional students. There were two non-traditional students, one was married, and each had a child. The effects of food insecurity among the non-traditional students may be different from those of the traditional students because their identity as college students may be affected by their other roles as parents and/or spouse and therefore the findings cannot be generalized to all college students. Future research should endeavor to recruit more non-traditional students and explore their experiences with food insecurity.

Another limitation of this study is that the interviewers were professionally trained student researchers, which may have made some participants uncomfortable and therefore affected their responses. It is possible that participants may have been biased by the interaction with students who doubled as researchers. During the interview and transcription process, the researchers noted long pauses and uncomfortable laughter which was interpreted as discomfort. There is stigma associated with food insecurity and it may have contributed to some participants feeling that their silent struggle is being exposed and they may have felt ashamed of disclosing some details of their experiences with food insecurity. In the current study, several measures were taken to attempt to reduce participant's discomfort, but it is impossible to fully eliminate the effect of the student interviewer. Participants were reassured that the information they provide will be confidential and their identifies would be concealed. They were also told that they could withdraw from the study at any time during the interview.

\section{Conclusion}

This research has highlighted the fact that food insecurity is an issue among college students at a public southern university. The underlying cause of food insecurity among students is limited finances and it is worsened by the increasing cost of attending college. Food insecurity affects student's academics, mental, physical and social health. Future research should investigate the longitudinal effects of food insecurity on academics, mental, physical and social health, from freshmen to senior year.

\section{References}

1. Coleman-Jensen A, Gregory CA, Rabbit M, Singh A (2017) Definitions of Food Security. US Department of Agriculture Economic Research Service, Washington, USA.

2. Coleman-Jensen A, Rabbit MP, Gregory CA, Singh A (2017) Household Food Security in the United States in 2016. US Department of Agriculture Economic Research Service, Washington, USA.

3. Bruening M, Brennhofer S, van Woerden I, Todd M, Laska M (2016) Factors Related to the High Rates of Food Insecurity among Diverse, Urban College Freshmen. J Acad Nutr Diet 116: 1450-7.

4. Chaparro MP, Zaghloul SS, Holck P, Dobbs J (2009) Food insecurity prevalence among college students at the University of Hawai'i at Manoa. Public Health Nutr 12: 2097-103.

5. Freudenberg N, Manzo L, Jones H, Kwan A, Tsui E, et al. (2011) Food Insecurity at CUNY: Results from a Survey of CUNY Undergraduate Students. A Report from: The Campaign for a Healthy CUNY.

6. Gaines A, Robb CA, Knol LL, Sickler S (2014) Examining the role of financial factors, resources and skills in predicting food security status among college students. Int J Consum Stud 38: 374-84.

7. Maroto ME, Snelling A, Linck H (2015) Food Insecurity Among Community College Students: Prevalence and Association with Grade Point Average. Community Coll J Res Pract 39: 515-26.

8. Morris LM, Smith S, Davis J, Null DB (2016) The Prevalence of Food Security and Insecurity Among Illinois University Students. J Nutr Educ Behav 48: 376-82. 9. Patton-López MM, López-Cevallos DF, Cancel-Tirado DI, Vazquez L (2014) Prevalence and Correlates of Food Insecurity Among Students Attending a Midsize Rural University in Oregon. J Nutr Educ Behav 46: 209-14.

10. Weinfield NS, Mills G, Borger C, Gearing M, Macaluso T, et al. (2014) Hunger in America 2014.

11. Goldrick-Rab S, Broton K, Eisenberg D (2015) Hungry to Learn: Addressing Food and Housing Insecurity Among the Undergraduates, USA.

12. National Center for Education Statistics (2017) The Condition of Education-Participation in Education. Undergraduate Enrollment, USA.

13. Alaimo K (2005) Food Insecurity in the United States: An Overview. Top Clin Nutr 20: 281-98.

14. Worthy SL, Jonkman J, Blinn-Pike L (2010) Sensation-Seeking, Risk-Taking, and Problematic Financial Behaviors of College Students. J Fam Econ Issues 31: $161-70$.

15. Becker CB, Middlemass K, Taylor B, Johnson C, Gomez F (2017) Food insecurity and eating disorder pathology. Int J Eat Disord 50: 1031-40.

16. Seligman HK, Laraia BA, Kushel MB (2010) Food insecurity is associated with chronic disease among low-income NHANES participants. J Nutr 140: $304-10$. 17. Mirabitur E, Peterson KE, Rathz C, Matlen S, Kasper N (2016) Predictors of college-student food security and fruit and vegetable intake differ by housing type. J Am Coll Heal 64: 555-64. 
18. Winkleby MA, Cubbin C (2004) Changing patterns in health behaviors and risk factors related to chronic diseases, 1990-2000. Am J Health Promot 19: 19-27. 19. Strauss AL, Corbin JM (1998) Basics of Qualitative Research : Techniques and Procedures for Developing Grounded Theory (3rd edn). Sage Publications.

20. Glaser BG, Strauss AL, Strutzel E (1968) The Discovery of Grounded Theory: Strategies for Qualitative Research. Nurs Res 17: 364.

21. Gall J, Gall M, Borg W (1999) Applying educational research: A practical guide. Longman Publishing Group.

22. Larson NI, Perry CL, Story M, Neumark-Sztainer D (2006) Food Preparation by Young Adults Is Associated with Better Diet Quality. J Am Diet Assoc 106: 2001-7.

23. Coleman-Jensen, AJ (2011) Working for Peanuts: Nonstandard Work and Food Insecurity Across Household Structure. J Fam Econ Issues 32: 84-97.

24. Berkowitz SA, Seligman HK, Choudhry NK (2014) Treat or Eat: Food Insecurity, Cost-related Medication Underuse, and Unmet Needs. Am J Med 27: 303-10.

25. Nielsen RB, Garasky S, Chatterjee S (2010) Food Insecurity and Out-of-Pocket Medical Expenditures: Competing Basic Needs. Fam Consum Sci Res J 39: 137-51.

26. Ma J, Baum S, Pender M, Bell DW (2015) Trends in College Pricing, 2015. Trends in Higher Education Series. College Board.

27. Bruening M, MacLehose R, Loth K, Story M, Neumark-Sztainer D (2012) Feeding a family in a recession: food insecurity among Minnesota parents. Am J Public Health 102: 520-6.

28. Dinour LM, Bergen D, Yeh MC (2007) The Food Insecurity-Obesity Paradox: A Review of the Literature and the Role Food Stamps May Play. J Am Diet Assoc 107: 1952-61.

29. Mi-Ting K, Peters Jr RJ, Ford K, Meshack A, Hill M (2013) The Relationship Between Perceived Psychological Distress, Behavioral Indicators and African American Female College Students Food Insecurity. Am J Health Stud 28: 127-33.

30. Fong K, Wright RA, Wimer C (2016) The cost of free assistance: Why low-income individuals do not access food pantries. J Sociol Soc Welf 43: 71.

31. Tsang S, Holt AM, Azevedo E (2011) An assessment of the barriers to accessing food among food-insecure people in Cobourg, Ontario. Chronic Dis Inj Can 31: $121-8$.

32. King J (2017) Food Insecurity Among College Students-Exploring the Predictors of Food Assistance Resource Use.

33. Hughes R, Serebryanikova I, Donaldson K, Leveritt M (2011) Student food insecurity: The skeleton in the university closet. Nutr Diet 68: 27-32.

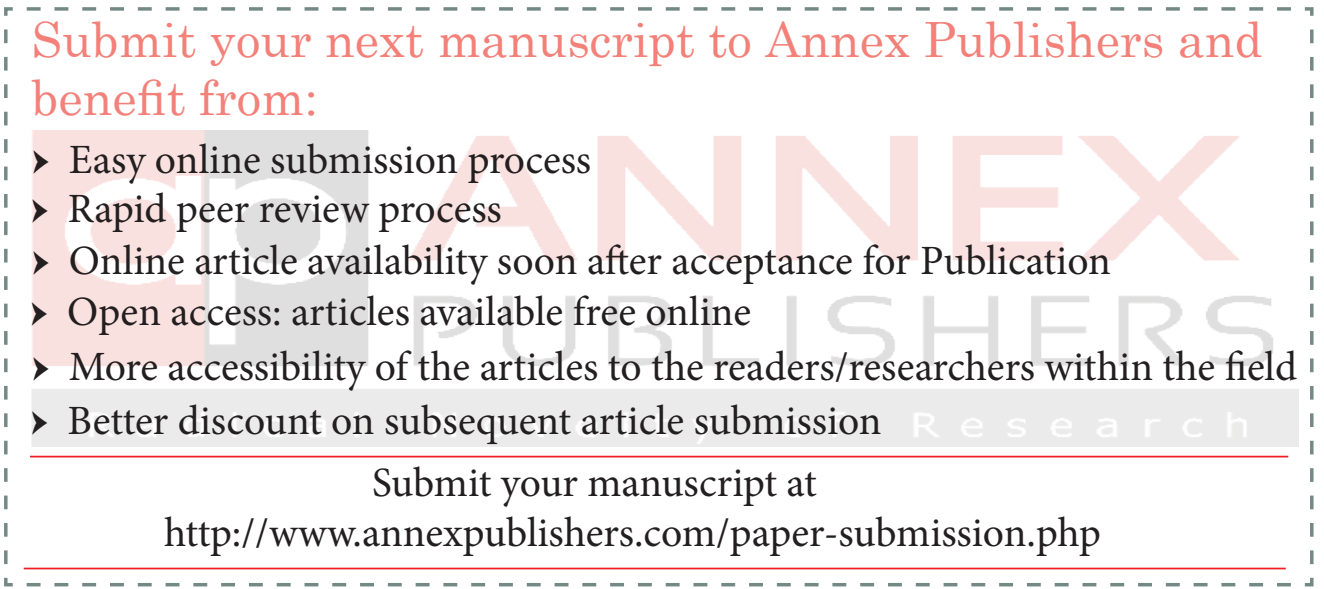

